\title{
Justification of the algorithm for selecting the parameters of the elastic lining of the drums of mine hoisting machines
}

\author{
Kostiantyn Zabolotnyi ${ }^{1 *}$, Olena Panchenko ${ }^{1}$, Oleksandr Zhupiiev ${ }^{1}$, and Jamil Sami Haddad ${ }^{2}$ \\ ${ }^{1}$ Dnipro University of Technology, Department of Mining Machines and Engineering, \\ 19 Yavornytskoho Ave., 49005 Dnipro, Ukraine \\ ${ }^{2}$ Al-Balqa Applied University, Department of Mechanical Engineering, Amman 11134 Jordan 15008
}

\begin{abstract}
When calculating the stress-strain state of a cylindrical drum of a mine hoisting machine loaded with a metal rope, the stiffness parameters of the elastic lining and frontal surface are taken into account. It is defined that, depending on the values of the radial and bending stiffness of the frontal surface, two zones can be distinguished. If the parameters of the frontal surface fall into the first of them, the stresses in the shell slightly differ from the stresses in the hinged supported shell. The second zone is characterized by a sharp (up to $70 \%$ ) increase in stresses. An algorithm has been developed for selecting rational parameters of a lined drum, which allows to reduce the stresses in the metal shell by up to $20 \%$.
\end{abstract}

\section{Introduction}

When mining, an important role is played by improving the competitiveness of mining engineering products. One of the ways to solve this problem is the development of methods for calculating the parameters of mining based on the use of computer and mathematical modeling methods. So in work [1], the structural and kinematic scheme of the diesel locomotive transmission is justified, and in work [2] a new conceptual approach is proposed for choosing the parameters of the transmission of wheeled vehicles.

Mine hoisting installations are the main mode of transport connecting the underground workings of the mine with the day surface, the main part of which is the mine hoisting machine (MHM). Modern MHM are the most powerful of all stationary equipment at the mine. The main type of MHM is a hoisting machine with cylindrical drums. The largest modern domestic drum MHM can provide useful payloads of up to 35 tons from a depth of up to $1000 \mathrm{~m}$ with a lifting speed of up to $20 \mathrm{~m} / \mathrm{s}$. The executive body of the MHM is a cylindrical drum - the most important element of the hoisting machine, taking high static loads.

The development of scientific methods to substantiate the design parameters of mine hoisting installations is the subject of scientific works, the analysis of which is given in work [3]. The researchers set the following tasks: to determine the influence of the geometric and stiffness characteristics of the reinforced drum structure [4], brake devices

\footnotetext{
*Corresponding author: mmf@ua.fm
} 
[5] on its stress-strain state, to develop the method for calculating design loads [6], to create engineering methods for determining the parameters of rational structures of working bodies of mine hoisting machines, to increase the cable capacity of a single-drum mine hoisting installation [7], to substantiate the parameters of equipment for dewatering ropes of mine hoisting installations [8], to improve the method of calculating power factors in the turns of the multilayer winding of rubber cable [9], to determine the effect of rubber cable parameters on the torsional stiffness of the winding body [10].

The authors of work [11] have proposed the use of non-metallic elastic lining of drums of mine hoisting machines from phenol-kapron material, as a means of changing the depth of lifting and increasing the service life of ropes.

The calculation of the lined drum when loading with a wound rope is characterized by the ability to obtain results in a semi-analytical form and to develop recommendations for choosing the parameters of the lining and frontal surface of the drums. That is why the justification of the algorithm for choosing the rational parameters of the elastic lining of the drums of mine hoisting machines is a topical scientific task.

\section{Methods}

A cylindrical drum of a shaft hoisting machine is a closed cylindrical shell on the surface, which has elastic lining [11], structurally composed of bars, laid along the forming shell of the drum and fixed with bolts. The drum is reinforced by stiffening rings and fastened to the front surfaces, which are connected to the shaft of the lifting machine through the hub.

Let the front surface be an averaged object having a bending and radial stiffness. The shell with lining bars can be represented as a two-layer cylindrical shell of constant thickness [11].

The calculation case of the drum is shown in Fig. 1. Here are indicated: 1 - the metal shell; 2 - the lining; 3 - the hub; $C_{r}$ and $C_{t}$ are the springs representing the averaged front surface, $l$ - the width of the drum, $R$ - the inner radius of the shell, $h_{0}$ - the thickness of the shell, $h_{f}$ - the lining thickness, $q$ - the uniform external pressure.

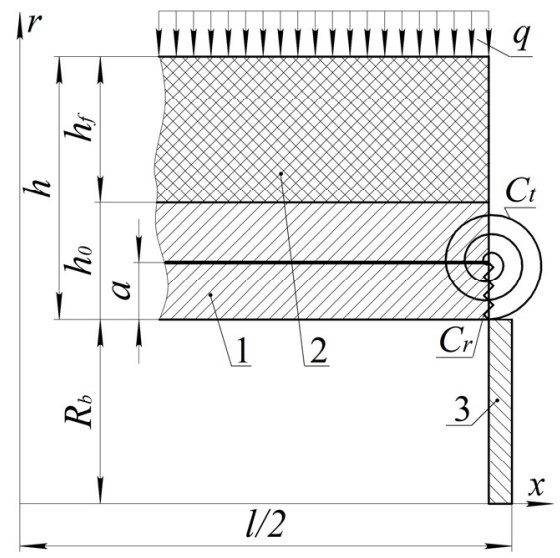

Fig. 1. The calculation scheme of a drum loaded with a wound rope.

In the cylindrical system of coordinates $r, y, x$, in which the axis $O x$ is directed along the axis of the drum, the following designations are valid: $w$ and $u$ - the components of movement along the axes $O r$ and $O x, \varepsilon_{r}, \varepsilon_{y}, \varepsilon_{x}$ are relative linear deformations, $\gamma_{x r}$ is angular deformation, $\sigma_{r}, \sigma_{x}, \sigma_{y}, \tau$ are the components of stress. 
The Cauchy relations are valid for the axisymmetric problem of the theory of elasticity

$$
\varepsilon_{r}=\frac{\partial w}{\partial r}, \quad \varepsilon_{y}=\frac{w}{r}, \quad \varepsilon_{x}=\frac{\partial u}{\partial x}, \quad \gamma_{x r}=\frac{\partial w}{\partial x}+\frac{\partial u}{\partial r}
$$

and the equations of equilibrium

$$
\frac{\partial}{\partial r}\left(r \cdot \sigma_{r}\right)+r \frac{\partial \tau}{\partial x}-\sigma_{y}=0 ; \quad \frac{1}{r} \cdot \frac{\partial}{\partial r}(r \cdot \tau)+\frac{\partial \sigma_{x}}{\partial x}=0,
$$

We introduce the variable $z$, counted from the inner surface of the shell,

$$
z=r-R
$$

and we will take into account that the shell is thin $\left(h<<R\right.$, where $h=h_{0}+h_{f}$ is the total thickness of the shell).

We will enumerate the Kirchhoff hypothesis: $\varepsilon_{z}=0, \gamma_{x r}=0, \sigma_{z}<\sigma_{x}, \quad \sigma_{z}<<\sigma_{y}$.

At a distance $a$ from the inner surface of the shell, the surface of reduction is introduced.

Then

$$
\begin{gathered}
w \equiv w(x) ; u(x, z) \equiv u(x)-(z-a) w^{\prime} ; \\
\sigma_{x}=\tilde{E}(z) \cdot\left(\varepsilon_{x}+\mu(z) \cdot \varepsilon_{y}\right) ; \sigma_{y}=\tilde{E}(z) \cdot\left(\varepsilon_{y}+\mu(z) \cdot \varepsilon_{x}\right),
\end{gathered}
$$

where $\widetilde{E}(z)=E(z) /\left(1-\mu(z)^{2}\right), \quad E \equiv E(z), \quad \mu \equiv \mu(z) \quad-$ variables on shell thickness, modulus of elasticity and Poisson's ratio; ...' - derivative with respect to $x$.

We also introduce the designation for thickness averaging operations:

$$
\langle\ldots\rangle=\int_{0}^{h}(\ldots) d z .
$$

The variation of the potential deformation energy of the shell with a length $\ell$ is represented as the sum of the longitudinal tension along the axis, the ring compression and the bending:

$$
\delta U=2 \pi \cdot R \int_{-0.5 \ell}^{0.5 \ell} \int_{0}^{h}\left(\sigma_{x} \cdot \delta \varepsilon_{x}+\sigma_{y} \cdot \delta \varepsilon_{y}\right) d z d x=2 \pi \cdot R \int_{-0.5 \ell}^{0.5 \ell}\left(N_{x} \cdot \delta u^{\prime}+N_{y} \cdot \frac{\delta w}{R}+M \cdot \delta w^{\prime \prime}\right) d x,
$$

where $N_{x}$ and $N_{y}$ are axial and annular forces; $M$ is a bending moment calculated by the formulas:

$$
N_{x}=B \cdot\left(u^{\prime}+v \frac{w}{R}\right)-K_{1} \cdot w^{\prime \prime} ; \quad N_{y}=B \cdot\left(u^{\prime} \cdot v+\frac{w}{R}\right)-K_{1} \cdot w^{\prime \prime} ; \quad M=D \cdot w^{\prime \prime}-K_{1} \cdot u^{\prime}-K \cdot \frac{w}{R} \text {. }
$$

In expressions (3), generalized stiffness characteristics are introduced: here $B$ is tensilecompression stiffness; $v$ is the averaged Poisson's ratio; $D$ is bending stiffness; $K$ and $K_{1}$ are coefficients linking bending with tension:

$$
B=\left\langle E^{\sim}\right\rangle, v=\frac{1}{B}\left\langle\mu \cdot E^{\sim}\right\rangle, D=\left\langle E^{\sim}(z-a)^{2}\right\rangle, K=\left\langle\mu \cdot E^{\sim}(z-a)\right\rangle, K_{1}=\left\langle E^{\sim}(z-a)\right\rangle .
$$

We dispose of the arbitrariness in the choice of the surface of reduction so that the coefficient $K_{1}$ turns to zero. Then expressions (4) take the form: 


$$
\begin{gathered}
a=\frac{\langle\widetilde{E} \cdot z\rangle}{\langle\widetilde{E}\rangle}=\frac{1}{B}\langle\widetilde{E} \cdot z\rangle, \quad K=\frac{1}{B}(\langle\widetilde{E}\rangle\langle\mu \cdot \widetilde{E} \cdot z\rangle-\langle\mu \cdot \widetilde{E}\rangle\langle\widetilde{E} \cdot z\rangle)=\langle\mu \cdot \widetilde{E} \cdot z\rangle-a \cdot B \cdot v, \\
D=\frac{1}{B}\left(\langle\widetilde{E}\rangle\left\langle\widetilde{E} \cdot z^{2}\right\rangle-\langle\widetilde{E} \cdot z\rangle^{2}\right)=\left\langle\widetilde{E} \cdot z^{2}\right\rangle-a^{2} \cdot B .
\end{gathered}
$$

We introduce the designations respectively for the modulus of elasticity and Poisson's ratio of the shell and lining: $E_{0}, \mu_{0}, E_{f}, \mu_{f}$. Then the generalized stiffness characteristics (5) will be presented in the form:

$$
\begin{gathered}
B=\tilde{E}_{0} h_{0}+\tilde{E}_{f} h_{f}, v=\frac{1}{B}\left(\tilde{E}_{0} h_{0} \mu_{0}+\tilde{E}_{f} h_{f} \mu_{0}\right), a=\frac{1}{2 B}\left(\tilde{E}_{f}\left(h^{2}-h_{0}^{2}\right)+\tilde{E}_{0} h_{0}^{2}\right), \\
K=\frac{1}{2}\left(\tilde{E}_{f} \mu_{f}\left(h^{2}-h_{0}^{2}\right)+\tilde{E}_{0} \mu_{f} h_{0}^{2}\right)-a \cdot B \cdot v, D=\frac{1}{3}\left(\tilde{E}_{f}\left(h^{3}-h_{0}^{3}\right)+\tilde{E}_{0} h_{0}^{3}\right)-a^{2} \cdot B .
\end{gathered}
$$

Let us state the difference between the bending of a two-layer beam and the axisymmetric bending of a two-layer shell. The beam is characterized by tensile stiffness $B$, bending stiffness $D$, and the coefficient of the link between bending and tension $K_{1}$. It is always possible to uniquely set the position of the surface of reduction so that the coupling coefficient is zero. Then, with pure bending, there will be no stretching of the surface of reduction. There are three types of deformations in the shell: ring compression, tension and buckling, as well as two coupling coefficients. Therefore, it is impossible to make all these types of deformations independent by choosing a single parameter and it is impossible to introduce the concept of a neutral surface. Choosing $K_{1}=0$ allows you to set a surface of reduction as one in which normal stresses do not occur during pure bending.

We can accept that $E_{f}<<E_{0}$ and $h_{f} \approx h_{0}$.

Let us introduce the designations: $e=\tilde{E}_{f} / \tilde{E}_{0}, \phi=h_{f} / h_{0}, B_{0}=\tilde{E}_{0} h_{0}, D_{0}=\tilde{E}_{0} h_{0}^{3} / 12$.

Taking into account that $e<<1$ we estimate the expressions of generalized stiffness characteristics:

$$
\begin{gathered}
B=B_{0}(1+e \phi) \approx B_{0}, \quad a=\frac{h_{0}(1+e \phi(\phi+2))}{2(1+e \phi)} \approx \frac{h_{0}}{2}, \\
v=\frac{\mu_{0}+\mu_{f} e \phi}{1+e \phi} \approx \mu_{0}\left(1+e \phi\left(\frac{\mu_{f}}{\mu_{0}}-1\right)\right) \approx \mu_{0}, \\
K=e \phi \frac{B_{0} h_{0}}{2(1+e \phi)} \cdot\left(\mu_{f}-\mu_{0}\right) \cdot(1+\phi) \approx 0, \\
D=\frac{D_{0}}{1+e \phi} \cdot\left(1+e \phi\left(4+6 \phi+4 \phi^{2}\right)+e^{4} \phi^{4}\right)=f \cdot D_{0} .
\end{gathered}
$$

With a significant difference in the moduli of elasticity of the lining and shell, it is permissible to assume $K=0$ and take into account the effect of the lining only on the value of cylindrical stiffness, i.e. $f$ coefficient:

$$
f=\frac{1}{1+e \phi} \cdot\left(1+e \phi\left(4+6 \phi+4 \phi^{2}\right)+e^{2} \phi^{4}\right) .
$$

Taking into account the potential energy of the deformation of the front surface $2 \pi r_{b} \cdot\left(C_{r} w \cdot d w+C_{t} w^{\prime} \cdot d w^{\prime \prime}\right)$ at $x=0.5 \ell$ and assuming that the front surfaces do not interfere 
with the longitudinal displacement of the shell, from symmetry considerations we obtain the equilibrium equations

$$
N_{x}^{\prime}=0 ; \quad M^{\prime \prime}+N_{y} / R=-q
$$

and boundary conditions:

at $x=0: \quad u=0, \quad w^{\prime}=0, \quad M^{\prime}=0$;

at $x=0.5 \ell: \quad N_{x}=0, \quad M=-C_{t} w^{\prime}, \quad M^{\prime}=C_{r} w$.

From the equality to zero of the longitudinal force along the entire length of the shell it follows that:

$$
u^{\prime}=-v \cdot w / R
$$

Then the expression for the annular force takes the form:

$$
N_{y}=B \cdot\left(1-v^{2}\right) \cdot \frac{w}{R}-K \cdot w^{\prime \prime}
$$

Let us introduce the designations: $B_{k}=\frac{B}{R^{2}}\left(1-v^{2}\right) \approx \frac{E_{0} h_{0}}{R^{2}}-$ annular stiffness; $\zeta=K / R \cdot D-$ minor parameter; $w_{*}=-q / B_{k}-$ uniform annular deflection of the shell; $\gamma-$ the variability of stress-strain state of the shell as a beam on an elastic basis:

$$
\gamma=\sqrt[4]{\frac{B_{k}}{4 D}}=\sqrt[4]{\frac{3\left(1-v^{2}\right) \cdot(1+e \phi)}{f \cdot R^{2} \cdot h_{0}^{2}}} \approx \frac{\sqrt[4]{3 \cdot\left(1-\mu_{0}^{2}\right) / f}}{\sqrt{R \cdot h_{0}}}
$$

$\bar{C}_{r}$ and $\bar{C}_{t}-$ relative radial and bending stiffness of the front surfaces

$$
\bar{C}_{r}=C_{r} / D, \quad \bar{C}_{t}=C_{t} / D
$$

$$
k_{t}=\frac{1}{1+2 \gamma \frac{D}{C_{t}}}, \quad k_{r}=\frac{1}{1+\frac{1}{2 \gamma} \cdot \frac{B_{k}}{C_{t}}}-\text { dimensionless stiffness coefficients. }
$$

The shell deflection equations can be written as:

$$
w^{\prime \prime \prime}-2 \zeta \cdot w^{\prime \prime}+4 \gamma^{4} \cdot w=4 \gamma^{4} \cdot w_{*} ;
$$

at $x=0: w^{\prime}=w^{\prime \prime \prime}=0$; at $x=0.5 \ell: w^{\prime \prime}-\zeta \cdot w+\bar{C}_{t} \cdot w^{\prime}=0, w^{\prime \prime \prime}-\zeta \cdot w^{\prime}+\bar{C}_{r} w=0$.

The solution of this equation we seek in the form

$$
w=w_{*}\left(1+A_{1} \cdot \operatorname{ch}(\alpha \cdot x) \cdot \cos (\beta \cdot x)+A_{2} \cdot \operatorname{sh}(\alpha \cdot x) \cdot \sin (\beta \cdot x)\right),
$$

where $\alpha=\sqrt{\gamma^{2}+0.5 \cdot \zeta} ; \beta=\sqrt{\gamma^{2}-0.5 \cdot \zeta}$.

Let us introduce the designations:

$$
\begin{aligned}
& C h=\operatorname{ch}(\alpha \cdot 0.5 \cdot \ell), C o=\cos (\beta \cdot 0.5 \cdot \ell), P_{1}=\alpha \cdot S h \cdot C o-\beta \cdot C h \cdot S i, \\
& S h=s h(\alpha \cdot 0.5 \cdot \ell), S i=\sin (\beta \cdot 0.5 \cdot \ell), P_{2}=\alpha \cdot C h \cdot S i+\beta \cdot S h \cdot C o .
\end{aligned}
$$

We will find the unknown constants $A_{1}$ and $A_{2}$ from the boundary conditions 


$$
\begin{gathered}
A_{1}\left(\bar{C}_{t} \cdot P_{1}-2 \alpha \beta \cdot S h \cdot S i\right)+A_{2}\left(\bar{C}_{t} \cdot P_{2}-2 \alpha \beta \cdot C h \cdot C o\right)=\zeta, \\
A_{1}\left(\bar{C}_{r} \cdot C h \cdot C o-2 \alpha \beta \cdot P_{2}\right)+A_{2}\left(\bar{C}_{r} \cdot S h \cdot S i-2 \alpha \beta \cdot P_{1}\right)=-\bar{C}_{r} .
\end{gathered}
$$

Knowing $w$, we will define the longitudinal movement

$$
u=-\frac{v \cdot w_{*}}{r_{b}} \cdot\left(x+\frac{1}{\alpha^{2}+\beta^{2}}\left(\alpha A_{1}-\beta A_{2}\right) \cdot \operatorname{sh}(\alpha x) \cdot \cos (\beta x)+\left(\beta A_{1}-\alpha A_{2}\right) \cdot \operatorname{ch}(\alpha x) \cdot \sin (\beta x)\right)
$$

deformations:

$$
\varepsilon_{x}=-v \cdot \frac{w}{r_{b}}-(z-a) \cdot w^{\prime \prime}, \quad \varepsilon_{y}=\frac{w}{r_{b}}
$$

stresses:

$$
\begin{gathered}
\sigma_{x}=\tilde{E}(z) \cdot\left((\mu(z)-v) \cdot \frac{w}{r_{b}}-(z-a) \cdot w^{\prime \prime}\right), \\
\sigma_{y}=\tilde{E}(z) \cdot\left((1-\mu(z) \cdot v) \cdot \frac{w}{r_{b}}-\mu(z) \cdot(z-a) \cdot w^{\prime \prime}\right)
\end{gathered}
$$

and the intensity of stresses

$$
\sigma_{i}=\sqrt{\sigma_{x}^{2}+\sigma_{y}^{2}-\sigma_{x} \cdot \sigma_{y}}
$$

We will write the stresses between the lining and the metal shell in the form:

$$
\begin{gathered}
\tau=-\int_{0}^{h_{0}} \sigma_{x}{ }^{\prime} d z=B_{0} \cdot\left(\frac{v-\mu_{0}}{r_{b}} w^{\prime}+\left(0.5 h_{0}-a\right) w^{\prime \prime \prime}\right), \\
\sigma_{r}=\int_{0}^{h_{0}}\left(\frac{\sigma_{y}}{r_{b}}-\tau(x, z)^{\prime}\right) d z=\frac{B_{0}}{r_{b}^{2}} \cdot\left(\left(1-v \mu_{0}\right) \cdot w+\left(\mu_{0} a-0.5 h_{0} \cdot v\right) \cdot w^{\prime \prime}+\frac{h_{0}}{6}\left(3 a-h_{0}\right) \cdot w^{\prime \prime \prime}\right) .
\end{gathered}
$$

The above formulas are implemented in the form of a program, the screen forms of which are shown in Figs. 2 and 3. From the analysis of the calculation results it can be seen that, in the general case, the stress-strain state in the shell can be divided (Figs. 2 and 3) into three ones: 1) in the middle of the shell, close to ring compression; 2) close to the axisymmetric bend of the hingedly supported shell; 3) a rapidly changing edge effect localized at front surfaces, which is characteristic of a rigidly clamped shell. The use of lining reduces stress in the shell by $20 \%$. If, at constant radial stiffness, we will gradually increase the bending stiffness, then at first the stresses will be even lower than with hinged support. Then, starting with the critical value of the bending stiffness $k_{t}{ }^{*}$ (as is well known, for semi-infinite single-layer shell with absolutely rigid radial supports $k_{t}^{*}=0.65$ ), the stresses in the shell sharply increase, approaching the stresses in the rigidly clamped shell.

From the above analysis it follows that the availability of the lining affects only an increase in the reduced bending stiffness of the shell. Let us take

Then $\alpha=\beta=\gamma$ and $\zeta=0$.

$$
D=D_{0} \cdot f ; K=0 ; \quad \mu_{0}=\mu_{f}=v .
$$

Let us introduce the designations: $\xi=\gamma \cdot x$ - dimensionless longitudinal coordinate; $\sigma_{k}=q \cdot R / h \quad-$ uniform annular compressive stresses; $\bar{\sigma}_{x}=\sigma_{x} / \sigma_{k}, \quad \bar{\sigma}_{y}=\sigma_{y} / \sigma_{k}$, $\bar{\sigma}_{i}=\sigma_{i} / \sigma_{k}-$ reduced bending and ring stresses and stress intensity, respectively; 
$\ell_{*}=0.5 \cdot \gamma \cdot \ell-$ reduced half-width of the drum.

Taking into account the introduced assumptions and designations, we can write down:

$$
w^{\prime \prime \prime \prime}+w=w_{*}
$$

at $\xi=0: w^{\prime}=w^{\prime \prime \prime}=0$; at $\xi=\ell_{*}:\left(1-k_{r}\right) \cdot w^{\prime \prime \prime}+2 k_{r} \cdot w=0,\left(1-k_{t}\right) \cdot w^{\prime \prime}-2 k_{t} \cdot w^{\prime}=0$.

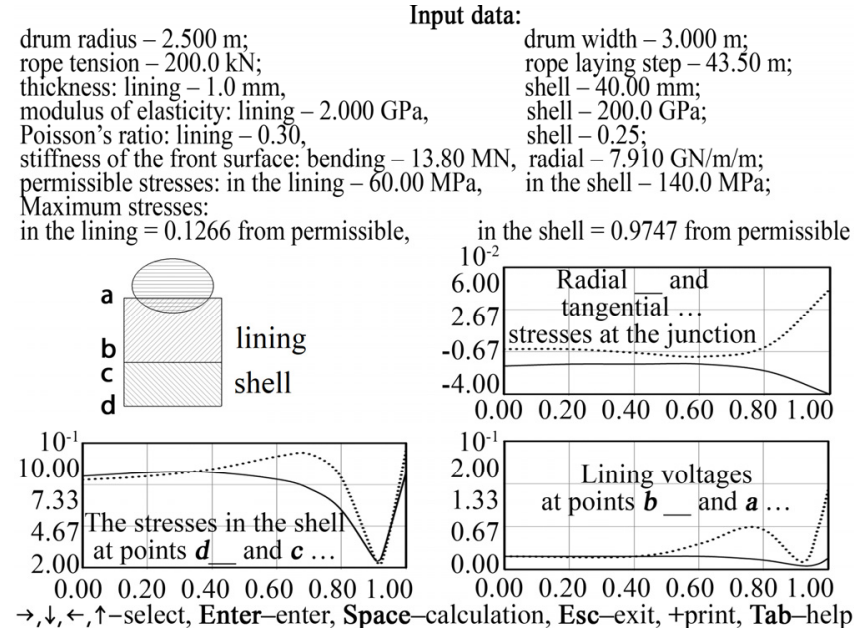

Fig. 2. Screen form of the program for determining stresses in the lined shell.

drum radius $-2.500 \mathrm{~m}$ Input data: rope tension $-200.0 \mathrm{kN}$; thickness: lining $-1.0 \mathrm{~mm}$, modulus of elasticity: lining permissible stresses: in the lining - 60.00 MPa, in the shell - 140.0 MPa; Maximum stresses:

in the lining $=0.0430$ from permissible,
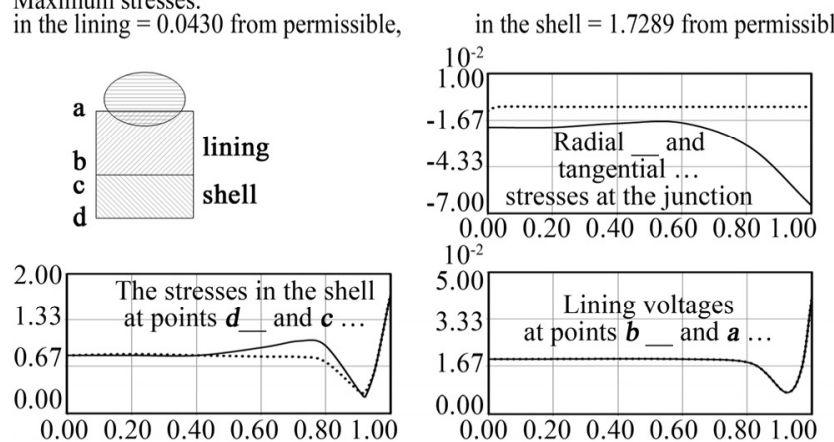

drum width $-3.000 \mathrm{~m}$; rope laying step $-43.50 \mathrm{~m}$; shell $-40.00 \mathrm{~mm}$; shell - 200.0 GPa; shell -0.25

in the shell $=1.7289$ from permissible

$\begin{array}{llllll}0.00 & 0.20 & 0.40 & 0.60 & 0.80 & 1.00\end{array}$

$\rightarrow, \downarrow, \leftarrow, \uparrow-$ select, Enter-enter, Space-calculation, Esc-exit, + print, Tab-help

Fig. 3. Screen form of the program for determining stresses in the non-lined shell.

Let us designate

$$
\begin{gathered}
C h=\operatorname{ch}\left(\ell_{*}\right) ; S h=\operatorname{sh}\left(\ell_{*}\right) ; C o=\cos \left(\ell_{*}\right) ; S i=\sin \left(\ell_{*}\right), \\
p_{11}=-\left(1-k_{t}\right) S h \cdot S i-k_{t} \cdot(C h \cdot S i-S h \cdot C o), p_{12}=\left(1-k_{t}\right) C h \cdot C o+k_{t} \cdot(C h \cdot S i+S h \cdot C o), \\
p_{21}=-\left(1-k_{t}\right) \cdot(C h \cdot S i+S h \cdot C o)-k_{r} \cdot C h \cdot C o, \quad p_{22}=-\left(1-k_{t}\right) \cdot(C h \cdot S i-S h \cdot C o)-k_{r} \cdot S h \cdot S i,
\end{gathered}
$$




$$
\operatorname{Del}=\left(p_{11} \cdot p_{22}-p_{12} \cdot p_{21}\right)^{-1}, \quad A_{1}=-k_{r} \cdot p_{12} \cdot \operatorname{Del} ; \quad A_{2}=k_{r} \cdot p_{11} \cdot \operatorname{Del}, \quad \lambda=\sqrt{3 / f \cdot\left(1-v^{2}\right)^{2}} .
$$

The final expressions for the deflection of the shell and the reduced stress values will take the form:

$$
\begin{aligned}
& w=w_{*} \cdot\left(1+A_{1} \cdot \operatorname{ch} \xi \cdot \cos \xi+A_{2} \cdot \operatorname{sh} \xi \cdot \sin \xi\right), \bar{\sigma}_{x}=\mp \lambda \cdot\left(A_{1} \cdot \operatorname{sh} \xi \cdot \sin \xi+A_{2} \cdot \operatorname{ch} \xi \cdot \cos \xi\right) \\
& \bar{\sigma}_{y}=-1-A_{1} \cdot \operatorname{ch} \xi \cdot \cos \xi-A_{2} \cdot \operatorname{sh} \xi \cdot \sin \xi, \bar{\sigma}_{i}=\sqrt{\bar{\sigma}_{y}^{2}+\left(\bar{\sigma}_{y}+v \cdot \bar{\sigma}_{x}\right)^{2}-\bar{\sigma}_{y}\left(\bar{\sigma}_{y}+v \cdot \bar{\sigma}_{x}\right)}
\end{aligned}
$$

which formed the basis of a simplified model.

Depending on the influence of the front surface on stresses, shells can be divided into long $\left(\ell_{*}>2\right)$, for which the stresses of uniform ring compression are minimal, and short, where the front surface can unload the shell.

In this case, the minimum values are reached when $k_{t}=0$ and $k_{r}=0$. For each non-zero value of radial stiffness of the front surface there is a range of bending stiffness values at which the stress intensity in the shell is several percent lower than with hinged support. For values of $k_{t}$ greater than the critical value of the bending stiffness $k_{t}^{*}$, the stresses in the shell increase sharply. In the lined drum, on the one hand, the total stress level decreases, and, on the other hand, the first area expands.

Fig. 4 presents the results of calculations of the reduced maximum stress intensity in the non-lined $(f=1)$ and lined $(f=2)$ drums of MHM depending on the reduced radial $\left(k_{r}\right)$ and bending $\left(k_{t}\right)$ stiffnesses of the front surfaces at $\ell_{*}>2$ : 1) for $\ell_{*}=1$ and $f=1$ the minimum of the stresses, equal to 1.0 , is reached at $k_{t}=0$ and $k_{r}=0$ (Fig. 4, a); 2) for $\ell_{*}=0.12$ and $f=1$ the minimum of stresses, equal to 0.44274 , is reached at $k_{t}=0$ and $k_{r}=0$ (Fig. $4 \mathrm{~b}$ ); 3) for $\ell_{*}=1$ and $f=2$ the minimum of stresses, equal to 1 , is reached at $k_{t}=0$ and $k_{r}=0$ (Fig. 4c).

$b$
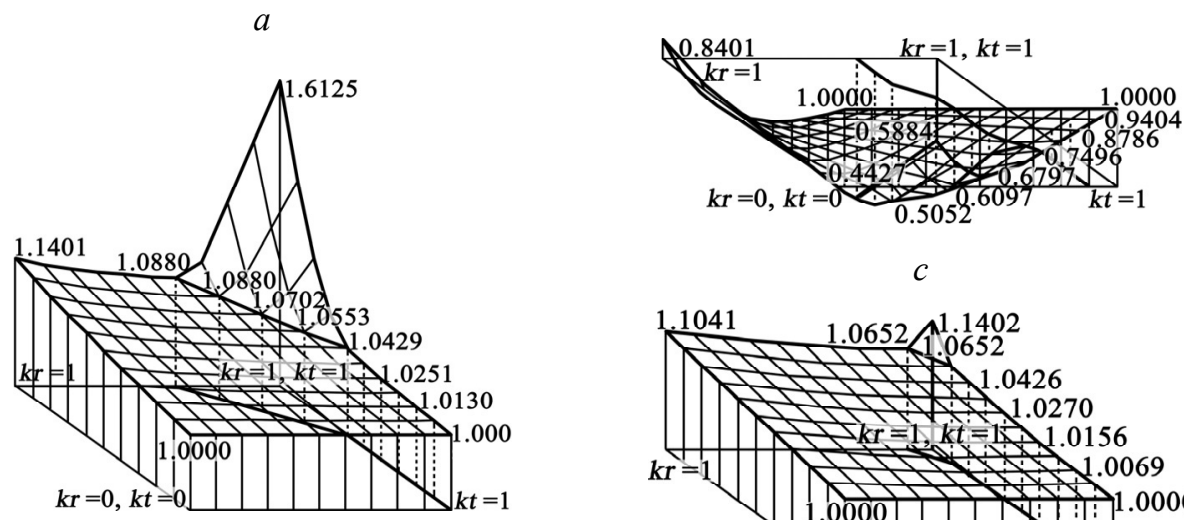

$c$

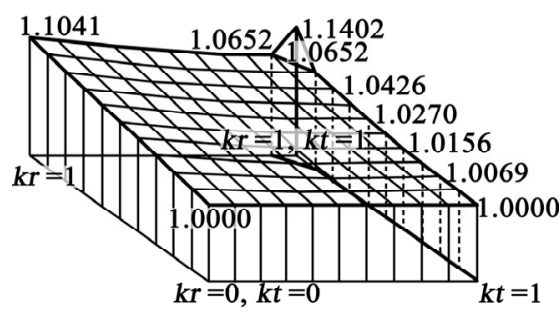

Fig. 4. Dependence of the maximum stress intensity in the lined shell on the reduced radial $k_{r}$ and bending $k_{t}$ stiffnesses of the front surface.

The results of calculations for short shells are shown in Fig. 5 (dimensionless reduced length $l=2 \pi / \ell_{*}$ is introduced here). The figure indicates: 1 - the maximum stress intensity in the non-lined shell $(f=1) ; 3$ and 5 - bending and radial stiffness of the front surfaces 
respectively; 2, 4 and 6 are the same values for the lined shell $(f=2)$. For a shell of a certain length $l$ with a given lining parameter $f$ from Fig. 5, it is possible to choose such values of the radial $k_{r}$ and the bending $k_{t}$ stiffnesses of the front surfaces at which the intensity of the stresses in the shell does not exceed the value $\bar{\sigma}_{i}$ displayed on the graph.

The following algorithm is recommended for choosing rational parameters of a lined drum with a helical groove under the rope. For given values of width 1 and drum diameter $d_{b}$, rope tension $P_{k}$ and deviation angle $U_{a}$, cutting depth $\mathrm{h}$, it is necessary to select a rational groove cutting step t. To do this, you can use Fig. 6 , which shows the dependences obtained in work [12].

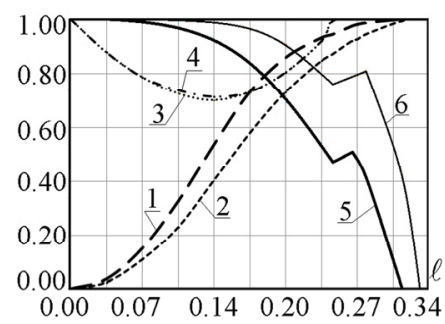

Fig. 5. Dependence of the maximum stress intensity in the lined and non-lined shells, as well as the corresponding reduced radial and bending stiffnesses of the front surface on the value of reduced length of the drum.

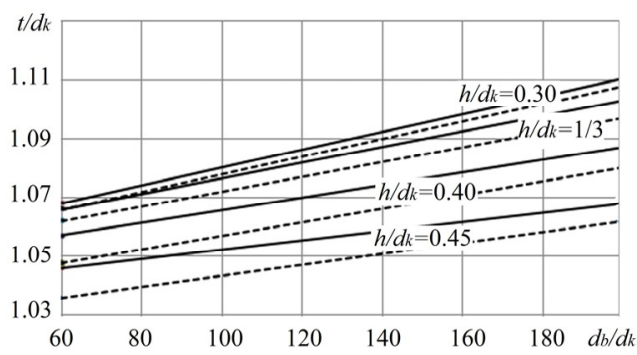

Fig. 6. Dependence of the laying step on the diameters of the drum and the rope.

Further, using the formula (8), it is necessary to calculate the parameter $\gamma$, and from the values of $\gamma$ and $l$ - to determine which class this shell belongs to. Then, using formulas (9), to calculate the bending stiffness of the front surface $C_{t}$ and the coefficient $k_{t}$, and from the expression (7) find the value of the parameter $f$ of the bending stiffness of the lined shell.

\section{Conclusions}

It has been proved that, depending on the values of the radial and bending stiffnesses of the front surface, two zones can be distinguished. If the parameters of the front surface fall into the first of them, the stresses in the shell slightly differ from the stresses in the hingedly supported shell. The second zone is characterized by a sharp (up to $70 \%$ ) increase in stresses. The use of the lining reduces the danger zone of the parameters of the front surface and, secondly, reduces (up to $20 \%$ ) the voltage in it.

An algorithm has been developed for selecting rational parameters of a lined drum which can significantly reduce the stresses in the shell.

Authors express gratitude to Yurii Ovchynnikov, the Lead Designer of the Novokramatorskyi Mashynobudivnyi Zavod for providing help and consultations during the work performance.

\section{References}

1. Taran, I. (2012). Interrelation of circular transfer ratio of double-split transmissions with regulation characteristic in case of planetary gear output. Naukovyi Visnyk Natsionalnoho Hirnychoho Universytetu, (3), 78-85.

2. Taran, I., \& Bondarenko, A. (2017). Conceptual approach to select parameters of hydrostatic and mechanical transmissions for wheel tractors designed for agrucultural opeations. Archives of 
transport, 41(1), 89-100.

3. Zabolotny, K., Zhupiev, O., \& Molodchenko, A. (2015). Analysis of current trends in development of mine hoists design engineering. New Developments in Mining Engineering 2015: Theoretical and Practical Solutions of Mineral Resources Mining, 175-179. https://doi.org/10.1201/b19901-32

4. Zabolotnyi, K.S., Zhupiiev, O.L., \& Sosnina, Ye.M. (2012). Study of deflected mode of mine winder split drums. Naukovyi Visnyk Natsionalnoho Hirnychoho Universytetu, (1), 82-88.

5. Zabolotnyi, K., Zhupiiev, O., \& Molodchenko, A. (2018). The effect of stiffness of shoe brakeelements on the distribution of contact pressures. Naukovyi Visnyk Natsionalnoho Hirnychoho Universytetu, (2), 39-46. https://doi.org/10.29202/nvngu/2018-2/3

6. Zabolotnyi, K., Zhupiiev, O., \& Molodchenko, A. (2017). Development of a model of contact shoe brake-drum interaction in the context of a mine hoisting machine. Mining of Mineral Deposits, 11(4), 38-45. https://doi.org/10.15407/mining11.04.038

7. Moskalyova, T.V., Polushyna, M.V. (2015). Cross way of fastening steel ropes to a singledrum mine hoisting plant with the location of pulleys on the same axis. Naukovyi Visnyk Natsionalnoho Hirnychoho Universytetu, (3), 56-62.

8. Zabolotny, K., Zinovyev, S., Zupiev, A., \& Panchenko, E. (2015). Rationale for the parameters equipment for rope dehydration of mining hoisting installations. New Developments in Mining Engineering 2015: Theoretical and Practical Solutions of Mineral Resources Mining, 275-283. https://doi.org/10.1201/b19901-49

9. Zabolotny, K., \& Panchenko, E. (2010). Definition of rating loading in spires of multilayer winding of rubberrope cable. New Techniques and Technologies in Mining, 223-229. https://doi.org/10.1201/b11329-38

10. Zabolotnyi, K.S., Panchenko, O.V., Zhupiiev, O.L., \& Polushyna, M.V. (2018). Influence of parameters of a rubber-rope cable on the torsional stiffness of the body of the winding. Naukovyi Visnyk Natsionalnoho Hirnychoho Universytetu, (5), 54-63. https://doi.org/10.29202/nvngu/2018$\underline{5 / 11}$

11. Zabolotnyi, K.S., Zhupiiev, A.L., \& Royzen, V.V. (1994). Novyy press-kompozit marki feneolokapron dlya gornorudnoy promyshlennosti. Metallurgical and Mining Industry, (1), 58-59.

12. Zabolotnyi, K.S. (1997). Razrabotka ratsionalnykh parametrov barabanov shakhtnykh pod'emnykh mashin s vnutrennimi tormozami na osnove metodov chislennogo modelirovaniya. Dnipropetrovsk: Systemni tekhnolohii. 